\title{
Feasibility of conducting a multicentre prospective study evaluating different physiotherapy methods for the treatment of mild idiopathic scoliosis patients using standardized methods of evaluation: call for a consensus
}

\author{
Josette Bettany-Saltikov", Jean Claude de Mauroy, Mark Farrugia \\ From 7th International Conference on Conservative Management of Spinal Deformities \\ Montreal, Canada. 20-22 May 2010
}

\section{Introduction}

The SOSORT physiotherapy consensus (2005) demonstrated that scoliosis specialists were in agreement that several features in the rehabilitation of patients with idiopathic scoliosis can be regarded as standard. The purpose of this study was to call for a preliminary consensus regarding the feasibility of conducting a multicentre prospective study evaluating different physiotherapy methods for the treatment of scoliosis using standardized methods of evaluation.

\section{Materials and methods}

The consensus questions were e-mailed to key members of SOSORT and colleagues specialising in scoliosis. The responses were analyzed quantitatively and qualitatively.

\section{Results}

Of the responses received, $50 \%$ were Doctors, $45 \%$ physiotherapists and $5 \%$ were Osteopaths $(n=20) .94 .7 \%$ of participants agreed that physiotherapy can limit scoliosis progression and 95\% agreed that it would be useful to conduct the proposed prospective study. $89.5 \%$ agreed that the initial inclusion criteria for the study should be female idiopathic scoliosis patients aged 11 to 13 (94.7\%). Risser scale $(0-1)$ had $84.2 \%$ responding positively when compared to Tanner pubic hair and Tanner breast $(68.4 \%$ and $52.6 \%$ respectively). The mean minimum and maximum Cobb angles were $13.9^{\circ}$ and $26.4^{\circ}$ (retained values of $15^{\circ}$ and $25^{\circ}$

Teesside University, Middlesbrough, United Kingdom

Full list of author information is available at the end of the article for the study). Of the respondents, $94.7 \%$ found the material to be useful. Many commented on the respiratory function, some feeling the need for high quality objective tests including spirometry, exercise testing and plethysmography, while others stated that mild scoliosis would have no effect on respiratory function. For the measurement of hip rotation asymmetry, pelvic and shoulder tilt the majority of participants agreed that they preferred to measure these in degrees, while for waist asymmetry, TRACE was preferred. $84.2 \%$ of respondents unanimously agreed with ATR Bunnel in degrees. $57.9 \%$ of respondents agreed with using the terms "rib hump" "frontal balance" (52.6\%) and "Sagittal profile" (63.2\%) in mm (10\% evoked the Rippstein plurimeter). The majority agreed on a multifactorial analytic and global asymmetric approach in an outpatient/community setting. Muscle strength testing was rigorously debated and evolved around the idea that strength is not an issue in scoliosis. The SRS-22 was preferred however comments included validating and adapting this further, and offers were forthcoming to aid the development of a universal trans-cultural psychological tool.

\section{Discussion}

This preliminary pilot consensus study (first round) clearly demonstrates the importance of conducting a multicentre prospective study and implementing article 22.2 of the SOSORT statutes proposed 4 years ago. This states "A database to collect important information about the results of exercises for the treatment of Scoliosis and other Spinal Deformities shall be created". This database would significantly help elucidate the 


\begin{tabular}{|c|c|c|c|c|}
\hline Item & Yes & No & Different & Missing \\
\hline $\begin{array}{l}\text { Do you think that physiotherapy can limit scoliosis } \\
\text { progression? }\end{array}$ & $94.7 \%$ & $5.3 \%$ & & \\
\hline Do you think it is useful to realize this prospective study? & $94.7 \%$ & $5.3 \%$ & & \\
\hline \multicolumn{5}{|c|}{ Do you agree with these inclusion criteria as for bracing? } \\
\hline Female & $89.5 \%$ & & & $10.5 \%$ \\
\hline Idiopathic & $89.5 \%$ & & & $10.5 \%$ \\
\hline $11-13$ years & $94.7 \%$ & & & $5.3 \%$ \\
\hline Tanner P 0-1 & $68.4 \%$ & & & $31.6 \%$ \\
\hline Tanner S 0.1 & $52.6 \%$ & & & $47.4 \%$ \\
\hline Risser 0-1 & $84.2 \%$ & & & $15.8 \%$ \\
\hline \multicolumn{5}{|c|}{ How do we define a minor scoliosis at risk of evolution? } \\
\hline - Minimum (Mean=13.9\%, retained $15^{\circ}$ ) & $\begin{array}{l}36.8 \% \\
10 \text { degrees }\end{array}$ & $\begin{array}{c}42.1 \% \\
15 \text { degrees }\end{array}$ & $\begin{array}{c}15.8 \% \\
20 \text { degrees }\end{array}$ & $5.3 \%$ \\
\hline - Maximum (Mean $26.4^{\circ}$, retained $25^{\circ}$ ) & $\begin{array}{c}10.5 \% \\
20 \text { degrees }\end{array}$ & $\begin{array}{c}52.6 \% \\
25 \text { degrees }\end{array}$ & $\begin{array}{c}31.6 \% \\
30 \text { degrees }\end{array}$ & $5.3 \%$ \\
\hline Are you OK with the material presented in useful links & $94.7 \%$ yes & $5.3 \%$ no & & \\
\hline $\begin{array}{l}\text { How can we evaluate the respiratory function of } \\
\text { scoliosis using simple tools? Do you agree with the } \\
\text { measurement of the lower chest perimeter (maximum)? }\end{array}$ & 26.3 agree & 15.8 don't & $\begin{array}{l}42.1 \% \\
\text { other }\end{array}$ & $15.8 \%$ \\
\hline How do you prefer to measure Rot hip asymmetry? & $84.3 \%$ deg & & & $15.8 \%$ \\
\hline How do you prefer to measure waist Asymmetry? & $26.3 \% \mathrm{~mm}$ & $\begin{array}{l}36.8 \% \\
\text { Trace }\end{array}$ & $\begin{array}{l}31.6 \% \\
\text { Both }\end{array}$ & $5.3 \%$ \\
\hline How do you prefer to measure Pelvic tilt? & $42.1 \%$ Deg & $5.3 \% \mathrm{~mm}$ & 36.8 both & $\begin{array}{l}10.5 \% \\
\text { other }\end{array}$ \\
\hline How do you prefer to measure Shoulder tilt? & $42.1 \% \mathrm{deg}$ & $5.3 \% \mathrm{~mm}$ & $\begin{array}{l}21.1 \% \\
\text { trace }\end{array}$ & \\
\hline \multicolumn{5}{|c|}{ Do you agree with using the following basic terminology? } \\
\hline Clinical Rib Hump (mm) & $57.9 \%$ yes & $5.3 \%$ Potsi & & $36.8 \%$ \\
\hline ATR Bunnel ( $\left.{ }^{\circ}\right)$ & $84.2 \%$ yes & & & $\begin{array}{l}15.8 \% \\
\text { mis }\end{array}$ \\
\hline Frontal Plane $(\mathrm{mm})$ & $52.6 \%$ yes & $5.3 \%$ No & & $42.1 \%$ \\
\hline Sagittal Profile $(\mathrm{mm})$ & $63.2 \%$ yes & $5.3 \%$ no & $\begin{array}{l}5.3 \% \text { each } \\
x \text {-ray/ } \\
\text { degree }\end{array}$ & $26.3 \%$ \\
\hline \multicolumn{5}{|c|}{ Which approach do you prefer? } \\
\hline Monofactorial/Multifactorial? & $21.1 \%$ mono & $\begin{array}{l}52.6 \% \\
\text { multi }\end{array}$ & $\begin{array}{l}10.5 \text { don't } \\
\text { know }\end{array}$ & $15.8 \%$ \\
\hline Analytic & $10.5 \%$ yes & $15.8 \%$ global & $26.3 \%$ both & $47.4 \%$ \\
\hline Symmetric & $5.3 \%$ & $10.5 \%$ asym & & $84.2 \mathrm{miss}$ \\
\hline Inpatient Centers (INP) vs outpatient (OP) centers? & $13.3 \mathrm{INP}$ & $60 \%$ OP & $6.7 \%$ both & $20 \%$ \\
\hline Muscle strength \& endurance Shirado/Sorenson test? & $5.3 \%$ Shirado & $\begin{array}{l}36.8 \% \\
\text { Sorenson }\end{array}$ & $\begin{array}{l}5.3 \text { don't } \\
\text { know }\end{array}$ & $26.3 \%$ \\
\hline $\begin{array}{l}\text { Do you prefer the adaptation of the SRS 22, the BSSQ or } \\
\text { the BrQ questionnaire? }\end{array}$ & $\begin{array}{c}63.2 \% \\
\text { SRS22 (ad) }\end{array}$ & $\begin{array}{l}10.5 \% \\
\text { Bssa }\end{array}$ & $\begin{array}{c}10.5 \% \\
\text { BRQ }\end{array}$ & $5.3 \%$ \\
\hline Do you wish to debate as a delege & $66.7 \%$ & $33.3 \%$ & & \\
\hline
\end{tabular}

Figure 1 Results of preliminary consensus study.

numerous questions cited in Figure 1 and above regarding the effectiveness of scoliosis specific exercises for the treatment of patients with mild scoliosis.

\section{Conclusion}

The full consensus still needs to go through a second round as well as validation by the board and participants during the next meeting. At this point full consensus should be reached on the proposed inclusion criteria, the management of scoliosis patients, the method as well as the objective and standardised evaluation. Some results could also be used for screening.
Published: 10 September 2010

doi:10.1186/1748-7161-5-S1-030

Cite this article as: Bettany-Saltikov et al.: Feasibility of conducting a multicentre prospective study evaluating different physiotherapy methods for the treatment of mild idiopathic scoliosis patients using standardized methods of evaluation: call for a consensus. Scoliosis 2010 5(Suppl 1):O30. 